\title{
Factors for Endoscopic Submucosal Dissection in Early Colorectal Neoplasms: A Single Center Clinical Experience in China
}

\author{
Yu-Qi He, Xin Wang, Ai-Qin Li, Lang Yang, Jian Zhang, Qian Kang, Shan Tang, Peng Jin and Jian-Qiu Sheng \\ Department of Gastroenterology, Beijing Military General Hospital, Beijing, China
}

Background/Aims: Early colorectal (CR) neoplasm can be cured by endoscopic submucosal dissection (ESD), but clinical experience and factors associated with complications from ESD for CR neoplasms in China have not been reported .

Methods: Seventy-eight cases of early CR neoplasm treated with endoscopic resection performed between December 2012 and December 2013 at Beijing Military General Hospital were included. Factors associated with ESD complications and procedure times were evaluated.

Results: The en bloc resection rate was $88.5 \%$ (69/78), tumor size was $32.1 \pm 10.7 \mathrm{~mm}$, and procedure time was $71.8 \pm 49.5 \mathrm{minutes}$. The major complication was perforation, which occurred in $8.97 \%$ of the ESD procedures. Multivariate logistic regression analysis indicated that only tumor size $(p=0.022)$ was associated with ESD perforation. Tumor size $(p<0.001)$ and the non-lifting sign $(p=0.017)$ were independent factors for procedure time, and procedure time $(p=0.016)$ was a key factor for en bloc resection. After a median 10 months (range, 4 to 16) of follow-up, no patients had local recurrence.

Conclusions: This study indicated that ESD is an applicable method for large early CR neoplasm in the colon and rectum. Tumor size and the non-lifting sign might be considerable factors for increased complication rate and procedural time of ESD.

Clin Endosc 2015;48:405-410

Key Words: Endoscopic submucosal dissection; Early colorectal neoplasms; Complications; Procedure time

\section{INTRODUCTION}

Endoscopic submucosal dissection (ESD) is a newly developed technology, through which a monoblock resection on the mucous or submucosa layer with a diameter larger than $20 \mathrm{~mm}$ can be achieved. As there are anatomical differences, ESD for colorectal (CR) neoplasms has met with some limitations compared to performing it in the upper gastrointestinal (GI) tract. Following recent technical improvements, early CR neoplasm can be cured by ESD in China, but clinical experience with and factors for outcomes following ESD for CR

Received: September 17, 2014 Revised: February 18, 2015 Accepted: March 13, 2015

Correspondence: Jian-Qiu Sheng

Department of Gastroenterology, Beijing Military General Hospital, Nanmenchang 5\#, Dongcheng District, Beijing 100700, China

Tel: +86-10-6672-1299, Fax: +86-10-6672-1168, E-mail: Jianqiu@263.net

(cc) This is an Open Access article distributed under the terms of the Creative Commons Attribution Non-Commercial License (http://creativecommons.org/ licenses/by-nc/3.0) which permits unrestricted non-commercial use, distribution, and reproduction in any medium, provided the original work is properly cited. neoplasms has been rarely reported. We report our experience and clinical outcomes in performing ESD using our own results.

\section{MATERIALS AND METHODS}

\section{Clinical data}

Data were collected from 78 cases of endoscopic resected CR neoplasms from December 2012 to December 2013 at Beijing Military General Hospital. Patient selection was according to suggested indication, ${ }^{1,2}$ as shown in Table 1. Before operation, patients underwent routine check electrocardiography, chest radiography, and hepatorenal function, coagulation function, and blood glucose measurements. Written informed consent was also given.

\section{Instruments and operation method}

Lesions were identified using high-magnification PCF- 
Q260AZI endoscopy (Olympus, Tokyo, Japan) with narrow-band imaging, and then were sprayed with $0.4 \%$ indigo carmine. We used a PCF-Q260AI endoscope (Olympus) with a transparent hood attached to the tip for ESD. The injection needles were from MTW Endoskopie (Wesel, Germany). Sodium hyaluronate (Shanghai Seebio Biotech. Inc., Shanghai, China) was injected into the submucosal layer to form a submucosal cushion, and a Dual-knife (KD 650U; Olympus) was used to dissect the lesion (Fig. 1). Carbon dioxide insufflation

Table 1. Indications of Endoscopic Submucosal Dissection

Lesions were difficult to remove en bloc with a snare

Non-granular laterally spreading tumor (LST-NG) or granular LST (LST-G) $\geq 20 \mathrm{~mm}$

Lesions with Vi type pit pattern

Lesions with large depressed type

Lesions with large elevated type suspected to be cancer ${ }^{\mathrm{a}}$

Mucosal lesions with a non-lifting sign caused by fibrosis due to biopsy or previous endoscopic mucosal resection Local residual early cancer after endoscopic resection

${ }^{a)} V_{N}$ type pit pattern or non-vascular area in surface without depressed type. was used during ESD to reduce patient discomfort. Anesthesia was induced with a small amount of propofol.

Immediate perforation was diagnosed when a small deep hole with visible omentum could be observed on the endoscopic monitor. Bleeding was defined as hemorrhage of visible large vessels, requiring the use of special hemostatic forceps. Procedure time was defined as from the first cut of the lesion to its complete removal.

\section{Postoperative management}

The resected specimen was stretched out and fixed onto a foam plastic board with pins. Its size was measured and pictures were taken. The specimen was then soaked in formaldehyde solution. Pathological study was performed on successive parallel slices with an interval of $2 \mathrm{~mm}$. En bloc resection was defined as one piece of tissue. R0 resection was defined as tumor-free lateral and vertical margins on histological examination. R0 resection without SM invasion deeper than $1,000 \mu \mathrm{m}$ or unfavorable histological risk factors related to lymph node metastasis (i.e., lymphovascular invasion, poor differentiation, or tumor budding) was considered a curative
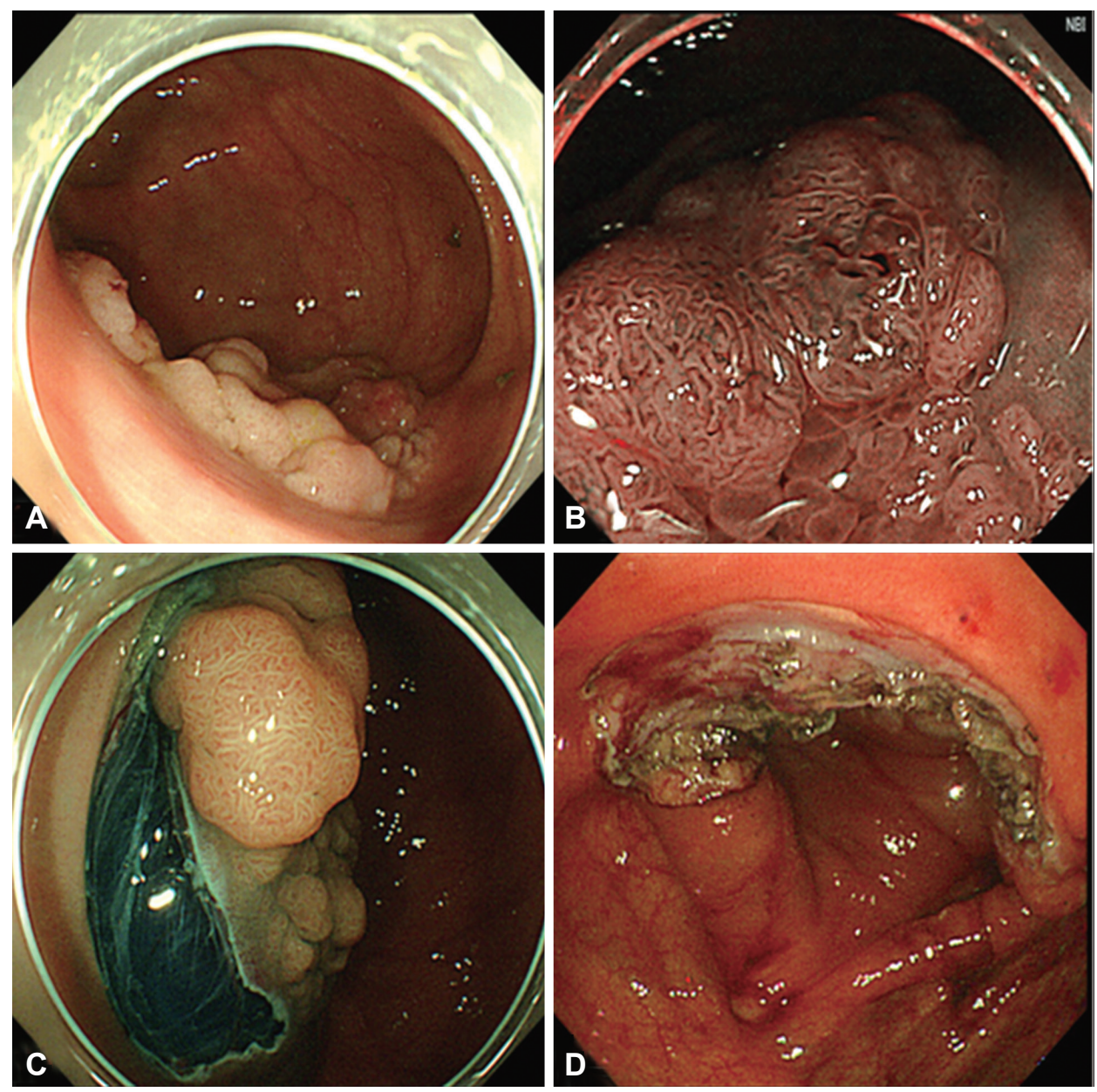

Fig. 1. (A) Laterally spreading non-granular type tumor in the cecum. (B) A narrow-band image view. (C) Submucosal injection and cutting using Dual-knife. (D) Artificial ulcer after endoscopic submucosal dissection. 
resection. Patients with non-curative resection were suggested to undergo surgical resection accompanied by lymph node dissection. $^{3,4}$

\section{Follow-up}

Colonoscopy was scheduled at 3,6, and 12 months after ESD, and then annually. Any suspicious lesions were confirmed on biopsy.

\section{Statistical analysis}

The statistical analysis was conducted with SPSS version 15.0 (SPSS Inc., Chicago, IL, USA). Independent two-sample $t$-test was used for continuous variables. Fisher exact test was used for categorical variables. The odds ratios (ORs) of factors significantly associated with complications were analyzed with logistic regression. Linear regression analysis was used to determine factors correlated with the ESD procedure time. Characteristics with $p<0.2$ were included in the univariate and multivariate regression models. Statistical significance was defined as values of $p<0.05$.

\section{RESULTS}

Patient characteristics and treatment results are described in Table 2. Histologically, there were 39 adenomas (50\%), 32 intramucosal adenocarcinomas (41\%), three adenocarcinomas with superficial submucosal invasion $(<1,000 \mu \mathrm{m}, 3.8 \%)$, two adenocarcinomas with deep submucosal invasion $(>1,000 \mu \mathrm{m}$, $2.5 \%)$, one adenocarcinoma with lymphovascular invasion (1.3\%), one adenocarcinoma with poor differentiation (1.3\%), and no cases with muscle layer invasion (0\%).

Immediate perforation occurred in seven patients (8.97\%) during the ESD procedure, of which five perforations were closed successfully with hemoclips (HX-610-090L; Olympus) during or after the procedure. Two cases were suspended, one of was subjected to surgical operation immediately, in whom histopathological examination confirmed a poor differentiation. The perforation in the other was successfully closed, and the patient treated with a second ESD procedure. Postoperative hemorrhage occurred in one patient (1.28\%), and was treated successfully with hemoclips (HX-610-090L). There was no significant procedure-related mortality in our study.

En bloc resection was performed in 69 cases, with a rate of 88.5\% (69/78). The remaining seven lesions were resected in two or more pieces by a combination of ESD and endoscopic mucosal resection (EMR), except for the two suspended cases. R0 resection rate was $85.9 \%$ (67/78), as an additional two cases were histologically judged to have positive lateral margins. The curative resection rate was $82.1 \%$ (64/78), with an addi-
Table 2. Characteristics and Treatment Results of the 78 Study Patients

\begin{tabular}{|c|c|}
\hline Characteristic & Value \\
\hline Age, yr & $62.1 \pm 10.3$ \\
\hline \multicolumn{2}{|l|}{ Sex } \\
\hline Male & $38(48.7)$ \\
\hline Female & $40(51.3)$ \\
\hline Tumor size, mm & $32.4 \pm 16.4$ \\
\hline \multicolumn{2}{|l|}{ Tumor location } \\
\hline Cecum & $3(3.8)$ \\
\hline Right colon & $20(25.6)$ \\
\hline Left colon & $14(17.9)$ \\
\hline Rectum & $41(52.6)$ \\
\hline \multicolumn{2}{|l|}{ Macroscopic type } \\
\hline LST-NG & $38(48.7)$ \\
\hline LST-G & $8(10.3)$ \\
\hline Is & $32(41.0)$ \\
\hline \multicolumn{2}{|l|}{ Histology } \\
\hline Adenoma & $39(50)$ \\
\hline Adenocarcinoma-m & $32(41)$ \\
\hline Adenocarcinoma-sml & $5(6.4)$ \\
\hline Adenocarcinoma-sm2 & $2(2.6)$ \\
\hline Adenocarcinoma-mp & 0 \\
\hline \multicolumn{2}{|l|}{ Non-lifting sign } \\
\hline Negative & $63(80.8)$ \\
\hline Positive & $15(19.2)$ \\
\hline Procedure time, min & $64.1 \pm 52.4$ \\
\hline En bloc resection & $69(88.5)$ \\
\hline $\mathrm{R} 0$ resection & $67(85.9)$ \\
\hline Curative resection & $64(82.1)$ \\
\hline Median follow-up, mo & $10(4-16)$ \\
\hline
\end{tabular}

Values are presented as mean $\pm \mathrm{SD}$, number (\%), or median (range). LST-NG, laterally spreading tumors-nongranular type; LST-G, laterally spreading tumors-granular type; Is, sessile type; m, mucosa; sm, submucosa; $\mathrm{mp}$, muscularis propria.

tional two patients with submucosal invasion of more than $1,000 \mu \mathrm{m}$ and one patient with lymphovascular invasion.

As shown in Table 3, factors affecting ESD perforations were tumor size ( $p=0.012$ ) and histology (adenocarcinoma-m; $p=0.166$ ). The multivariate logistic regression model indicated that only tumor size $(p<0.05)$ was associated with ESD perforations (OR, 1.45; 95\% confidence interval, 1.06 to 2.00; $p=0.022$ ). The mean procedure time was $64.1 \pm 52.4$ minutes. In Table 4, multivariate linear regression indicated that tumor size $(p<0.001)$ and the non-lifting sign $(p=0.017)$ were key factors for procedure time. In Table 5, we also analyzed factors 
Table 3. Univariate and Multivariate Analyses of Factors Affecting Perforation in Endoscopic Submucosal Dissection ( $\mathrm{n}=78)$

\begin{tabular}{|c|c|c|c|c|}
\hline \multirow{2}{*}{ Variable } & \multicolumn{2}{|c|}{ Univariate } & \multicolumn{2}{|c|}{ Multivariate } \\
\hline & OR $(95 \% \mathrm{CI})$ & $p$-value & OR $(95 \% \mathrm{CI})$ & $p$-value \\
\hline Age, yr & $0.991(0.92-1.06)$ & 0.659 & & \\
\hline \multicolumn{5}{|l|}{ Sex } \\
\hline Female & 1 & & & \\
\hline Male & $1.27(0.15-1.91)$ & 0.781 & & \\
\hline Tumor size, $\mathrm{mm}$ & $1.02(0.98-1.06)$ & 0.012 & $1.45(1.06-2.00)$ & 0.022 \\
\hline \multicolumn{5}{|l|}{ Tumor location } \\
\hline Cecum & $1.79(0.19-5.75)$ & 0.581 & & \\
\hline Right colon & $2.69(0.26-38.28)$ & 0.533 & & \\
\hline Left colon & $1.01(0.95-1.06)$ & 0.646 & & \\
\hline Rectum & 1 & & & \\
\hline \multicolumn{5}{|l|}{ Macroscopic type } \\
\hline LST-NG & $1.07(0.2-5.68)$ & 0.942 & & \\
\hline LST-G & $3.67(0.5-26.81)$ & 0.22 & & \\
\hline Is & 1 & & & \\
\hline \multicolumn{5}{|l|}{ Histology } \\
\hline Adenoma & 1 & & 1 & \\
\hline Adenocarcinoma-m & $0.70(0.14-3.47)$ & 0.166 & $0.89(0.66-1.08)$ & 0.345 \\
\hline Adenocarcinoma-sm & $0.42(0.04-4.48)$ & 0.474 & $0.53(0.14-3.48)$ & 0.637 \\
\hline \multicolumn{5}{|l|}{ Non-lifting sign } \\
\hline Positive & $1.75(0.2-15.41)$ & 0.614 & & \\
\hline Negative & 1 & & & \\
\hline Procedure time & $0.99(0.98-1.01)$ & 0.350 & & \\
\hline
\end{tabular}

OR, odds ratio; CI, confidence interval; LST-NG, laterally spreading tumors-nongranular type; LST-G, laterally spreading tumors-granular type; Is, sessile type; $\mathrm{m}$, mucosa; sm, submucosa.

Table 4. Multivariate Analysis of Factors Affecting Endoscopic Submucosal Dissection Procedure Time

\begin{tabular}{|c|c|c|c|c|}
\hline \multirow{2}{*}{ Variable } & \multicolumn{2}{|c|}{ Univariate } & \multicolumn{2}{|c|}{ Multivariate } \\
\hline & $\beta \pm \mathrm{SE}$ & $p$-value & $\beta \pm \mathrm{SE}$ & $p$-value \\
\hline Age, yr & $0.07 \pm 0.42$ & 0.872 & & \\
\hline \multicolumn{5}{|l|}{ Sex } \\
\hline Female & $-1.99 \pm 8.32$ & 0.812 & & \\
\hline Male & 1 & & & \\
\hline Tumor size, mm & $24.12 \pm 2.94$ & 0.000 & $25.04 \pm 3.33$ & 0.000 \\
\hline \multicolumn{5}{|l|}{ Tumor location } \\
\hline Cecum & $-19.68 \pm 31.24$ & 0.531 & $-3.43 \pm 22.61$ & 0.880 \\
\hline Right colon & $-20.78 \pm 14.24$ & 0.149 & $1.12 \pm 11.13$ & 0.920 \\
\hline Left colon & $4.10 \pm 16.17$ & 0.800 & $12.33 \pm 11.66$ & 0.294 \\
\hline Rectum & 1 & & & \\
\hline \multicolumn{5}{|l|}{ Macroscopic type } \\
\hline LST-NG & $24.77 \pm 12.12$ & 0.145 & $22.29 \pm 9.12$ & 0.301 \\
\hline LST-G & $42.04 \pm 19.92$ & 0.038 & $-7.01 \pm 16.96$ & 0.681 \\
\hline Is & 1 & & & \\
\hline \multicolumn{5}{|l|}{ Histology } \\
\hline Adenoma & 1 & & & \\
\hline Adenocarcinoma-m & $1.69 \pm 17.30$ & 0.923 & & \\
\hline Adenocarcinoma-sm & $-8.80 \pm 13.97$ & 0.531 & & \\
\hline \multicolumn{5}{|l|}{ Non-lifting sign } \\
\hline Positive & $-37.98 \pm 10.70$ & 0.001 & $-31.89 \pm 15.03$ & 0.017 \\
\hline Negative & 1 & & & \\
\hline
\end{tabular}

LST-NG, laterally spreading tumors-nongranular type; LST-G, laterally spreading tumors-granular type; Is, sessile type; m, mucosa; sm, submucosa. 
Table 5. Factors Affecting the En bloc Resection

\begin{tabular}{|c|c|c|}
\hline \multirow{2}{*}{ Variable } & \multicolumn{2}{|c|}{ Univariate } \\
\hline & OR $(95 \% \mathrm{CI})$ & $p$-value \\
\hline Age, yr & $1.03(0.96-1.10)$ & 0.473 \\
\hline \multicolumn{3}{|l|}{ Sex } \\
\hline Female & 1 & \\
\hline Male & $1.21(0.3-4.91)$ & 0.788 \\
\hline Tumor size, $\mathrm{mm}$ & $0.98(0.94-1.01)$ & 0.244 \\
\hline \multicolumn{3}{|l|}{ Tumor location } \\
\hline Cecum & $2.01(0.69-10.58)$ & 0.645 \\
\hline Right colon & $1.03(0.18-37.57)$ & 0.730 \\
\hline Left colon & $3.16(0.26-28.28)$ & 0.362 \\
\hline Rectum & 1 & \\
\hline \multicolumn{3}{|l|}{ Macroscopic type } \\
\hline LST-NG & $0.73(0.18-2.96)$ & 0.654 \\
\hline LST-G & $2.01(1.93-5.36)$ & 0.599 \\
\hline Is & 1 & \\
\hline \multicolumn{3}{|l|}{ Histology } \\
\hline Adenoma & 1 & \\
\hline Adenocarcinoma-m & $1.95(0.36-10.59)$ & 0.440 \\
\hline Adenocarcinoma-sm & $0.68(0.12-3.93)$ & 0.671 \\
\hline \multicolumn{3}{|l|}{ Non-lifting sign } \\
\hline Positive & $2.38(0.52-10.85)$ & 0.259 \\
\hline Negative & 1 & \\
\hline Procedure time & $0.99(0.98-1.00)$ & 0.016 \\
\hline
\end{tabular}

OR, odds ratio; CI, confidence interval; LST-NG, laterally spreading tumors-nongranular type; LST-G, laterally spreading tumors-granular type; Is, sessile type; m, mucosa; sm, submucosa.

affecting the en bloc resection rate, the results of which indicated that procedure time $(p=0.016)$ was a key factor associated with en bloc resection. The median follow-up duration was 10 months (range, 4 to 16). No patients had local recurrence after ESD.

\section{DISCUSSION}

The common methods of endoscopic minimally invasive therapy for early GI lesions include EMR and ESD. EMR is suitable for smooth lesions with diameters from 5 to $20 \mathrm{~mm}$. When the lesion diameter is more than $20 \mathrm{~mm}$, endoscopic piecemeal mucosal resection (EPMR) has previously been accepted as a treatment modality. However, pathological assessment is more difficult, and the risk of incomplete resection or recurrence is increased. ${ }^{5,6}$

ESD is a newly developed technique, through which a monoblock resection to the mucous or submucosa layer with a diameter larger than $20 \mathrm{~mm}$ can be achieved. According to recently published studies, the en bloc resection rate was $80 \%$ to $98.6 \%$, and the complete resection rate was $70 \%$ to $98.6 \%$. The en bloc and R0 resection rates in this study were $88.5 \%$ and $85.9 \%$, respectively. With a higher rate of en bloc resection, histological evaluation of the resected specimens can be done, especially for suspected malignant lesions. Histological diagnosis confirms that cases with a submucosal infiltration depth of tumor cells less than $1,000 \mu \mathrm{m}$, and with no evidence of lymphovascular invasion or poor differentiation, may have a lower rate of lymph node metastasis, and surgery can be avoided. In this study, surgery was suggested for two patients with submucosal invasion of more than $1,000 \mu \mathrm{m}$, and one patient with lymphovascular invasion.

The rate of perforation was $8.97 \%$. All perforations were closed successfully with hemoclips during or after the procedure, except for one case with poor differentiation. The multivariate logistic regression model indicated that only tumor size was associated with ESD perforation. In our study, a non-lifting sign was disclosed in $19.2 \%$ of all ESD lesions. Reasons for this were biopsy, tumor infiltration, and residual tumor after previous treatment with EMR or EPMR. Multivariate analyses revealed that tumor size and the non-lifting sign were key factors for operative time. ESD is a relatively long procedure, and the procedure time was a key factor for en bloc resection. Taken together, tumor size and the non-lifting sign might be considerable factors leading to a long operative time and a lower rate of en bloc resection.

The implementation of ESD in the colon is more challenging. It needs more advanced endoscope technology and a longer learning cycle. The operation complexity and the complication occurrence rate may vary with the tumor position, presence of the non-lifting sign, or tumor size. ${ }^{2}$ In this study, only tumor size was shown to be associated with perforations. Differences with the previous study might be due to the lower number of patients included, $8.7 \%$ versus 3.8\% in the cecum, and $20.7 \%$ versus $19.2 \%$ with the non-lifting sign. On the other hand, this could also be because the endoscopists had more experience with the technique of ESD in the colon and rectum. Procedures were performed over a yearlong period by our endoscopists. Before and during the study period, more than 300 gastric, esophageal and ESD procedures for $\mathrm{CR}$ neoplasms were performed, reflecting the endoscopists' ESD expertise.

In conclusion, our study re-confirmed that ESD is an effective technique for large superficial CR tumors. ESD performed by experienced endoscopists can be a safe and effective procedure for treating large CR neoplastic lesions even in positions that may be more difficult to treat with an 
operation. Further studies are needed to confirm our results for ESD for CR tumors, and a prospective randomized trial is needed for comparing the performance of ESD in different positions.

\section{Conflicts of Interest}

The authors have no financial conflicts of interest.

\section{Acknowledgments}

This work was conducted with the support of funding provided by the Special Research Found for Health Care of PLA, China (Grant No. 12BJZ04).

\section{REFERENCES}

1. Shono T, Ishikawa K, Ochiai Y, et al. Feasibility of endoscopic submucosal dissection: a new technique for en bloc resection of a large superfi- cial tumor in the colon and rectum. Int J Surg Oncol 2011;2011:948293.

2. Tseng MY, Lin JC, Huang TY, et al. Endoscopic submucosal dissection for early colorectal neoplasms: clinical experience in a tertiary medical center in Taiwan. Gastroenterol Res Pract 2013;2013:891565.

3. Ueno $\mathrm{H}$, Mochizuki $\mathrm{H}$, Hashiguchi $\mathrm{Y}$, et al. Risk factors for an adverse outcome in early invasive colorectal carcinoma. Gastroenterology 2004;127:385-394.

4. Rahal R, Klein-Geltink J, Forte T, Lockwood G, Bryant H. Measuring concordance with guidelines for the diagnosis and treatment of colon cancer. Curr Oncol 2013;20:227-229.

5. Terasaki M, Tanaka S, Oka S, et al. Clinical outcomes of endoscopic submucosal dissection and endoscopic mucosal resection for laterally spreading tumors larger than $20 \mathrm{~mm}$. J Gastroenterol Hepatol 2012;27:734-740.

6. Seo GJ, Sohn DK, Han KS, et al. Recurrence after endoscopic piecemeal mucosal resection for large sessile colorectal polyps. World J Gastroenterol 2010;16:2806-2811.

7. Endoscopic Classification Review Group. Update on the paris classification of superficial neoplastic lesions in the digestive tract. Endoscopy 2005;37:570-578 